Author has nothing to disclose with regard to commercial support.

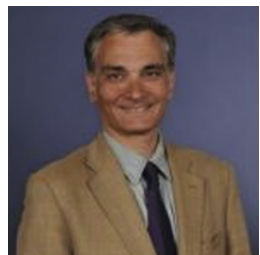

\section{ELASTIN DEFICIENCY IN WILLIAMS SYNDROME MAY EXPLAIN POSTOPERATIVE MAJOR ADVERSE CARDIAC EVENTS \\ To the Editor:}

Dr Christoph P. Hornik and colleagues ${ }^{1}$ established, in their paper published in the Journal in June 2015, that major adverse cardiac events after cardiac surgery are common in patients who have Williams syndrome. They suggest a multifactorial explanation.

Williams syndrome is now recognized as a clinical manifestation of elastin deficiency, ${ }^{2}$ with a mutation sequenced in chromosome 7q11.23. Elastin, an extracellular matrix protein, is the major component of elastic fibers responsible for the elastic and rheologic properties of arteries. ${ }^{3,4}$ Normal deposition of elastin is a critical event in vessel development. ${ }^{5}$ Defective elastin has been implicated in aortic dissection for some time. ${ }^{6}$

Therefore, consideration of pathologic elastin as one factor that may explain the findings of Dr Hornik and colleagues is prudent.

Aristotle D. Protopapas, MSc (DIC), FRCS (Glasg) Department of Medicine, Imperial College London London, United Kingdom

\section{References}

1. Hornik CP, Collins RT II, Jaquiss RD, Jacobs JP, Jacobs ML, Pasquali SK, et al. Adverse cardiac events in children with Williams syndrome undergoing cardiovascular surgery: an analysis of the Society of Thoracic Surgeons Congenital Heart Surgery Database. J Thorac Cardiovasc Surg. 2015;149:1516-22.e1.

2. Zarate YA, Lepard T, Sellars E, Kaylor JA, Alfaro MP, Sailey C, et al. Cardiovascular and genitourinary anomalies in patients with duplications within the Williams syndrome critical region: phenotypic expansion and review of the literature. Am J Med Genet A. 2014;164A:1998-2002.

3. Faury G, Garnier S, Weiss AS, Wallach J, Fülöp T Jr, Jacob MP, et al. Action of tropoelastin and synthetic elastin sequences on vascular tone and on free $\mathrm{Ca} 2+$ level in human vascular endothelial cells. Circ Res. 1998;82:328-36.

4. Robert L, Jacob MP, Fülöp T Jr. Elastin in blood vessels. Ciba Found Symp. 1995; 192:286-99.

5. Davis EC. Stability of elastin in the developing mouse aorta: a quantitative radioautographic study. Histochemistry. 1993;100:17-26.

The Editor welcomes submissions for possible publication in the Letters to the Editor section that consist of commentary on an article published in the Journal or other relevant issues. Authors should: • Include no more than 500 words of text, three authors, and five references. $\bullet$ Type with double-spacing. $\bullet$ See http://jtcs.ctsnetjournals.org/ misc/ifora.shtml for detailed submission instructions. • Submit the letter electronically via jtcvs.editorialmanager.com. Letters commenting on an article published in the JTCVS will be considered if they are received within 6 weeks of the time the article was published. Authors of the article being commented on will be given an opportunity of offer a timely response ( 2 weeks) to the letter. Authors of letters will be notified that the letter has been received. Unpublished letters cannot be returned.
6. Cattell MA, Hasleton PS, Anderson JC. Increased elastin content and decreased elastin concentration may be predisposing factors in dissecting aneurysms of human thoracic aorta. Cardiovasc Res. 1993;27:76-81.

http://dx.doi.org/10.1016/j.jtcvs.2015.07.031

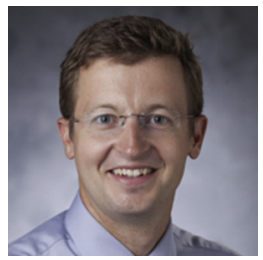

\section{COMBINING CLINICAL DATABASES WITH GENETIC STUDIES TO HELP ADVANCE THE CAUSATION MODEL OF CONGENITAL HEART DISEASE Reply to the Editor:}

We thank Dr Protopapas for his thoughtful comments on our article "Major Adverse Cardiac Events in Children With Williams Syndrome Undergoing Cardiovascular Surgery: An Analysis of the Society of Thoracic Surgeons Congenital Heart Surgery Database." The hypothesis brought forward that elastin pathology is at the source of the abnormal vascular development seen in some patients with Williams syndrome seems well founded and worthy of continued study.

The promise of genetic information driving clinical decision making in congenital heart disease is appealing, particularly in high-risk patients with variable outcomes, such as those with Williams syndrome. ${ }^{2}$ Turning this promise into reality first requires establishing strong genotype-phenotype relationships. This will best be accomplished by routinely collecting and analyzing genetic data from large patient cohorts. ${ }^{3}$ In a subsequent step, the identified genetic information will need to be linked to a clinical outcome. Although the routine collection of genetic information is undoubtedly complex and requires a strong infrastructure, the overall task may be simplified by using existing clinical outcomes data sources. The Society of Thoracic Surgeons Congenital Heart Surgery Database, as the largest and most comprehensive congenital heart surgery data repository in the world, is an excellent source of such data. ${ }^{4}$

Given the variability in clinical outcomes described in our study and the potential genetic mechanism hypothesized by Dr Protopapas and others, patients with Williams syndrome may be an ideal population in whom to prospectively study genetic sample collection combined with standard of care clinical outcomes data. If successful in identifying a genotype-phenotype relationship, such a study might demonstrate the feasibility and efficiency of a novel mechanism to help advance the causation model of congenital heart disease.

Christoph P. Hornik, MD, MPH ${ }^{a, b}$

R. Thomas Collins II, MD Robert D. B. Jaquiss, $M D^{a, b}$ Jeffrey P. Jacobs, $M D^{d}$ Marshall L. Jacobs, $M D^{e}$ Sara K. Pasquali, $M D^{f}$ 
Research reported in this publication was supported by the National Center for Advancing Translational Sciences of the National Institutes of Health under Award Number UL1TR001117 (to C.P.H. and K.D.H.) and by the National Heart, Lung, and Blood Institute under Award Number K08HL103631 (to S.K.P.). The content is solely the responsibility of the authors and does not necessarily represent the official views of the National Institutes of Health, which had no role in study design; the collection, analysis, and interpretation of data; the writing of the report; or the decision to submit the manuscript for publication.

Authors have nothing to disclose with regard to commercial support. and colleagues, in the April 2015 edition of the Journal. ${ }^{1}$

We agree with the authors that an improved technique is necessary for localization of nonvisceral surface pleural nodules. Improvement of the intraoperative localization of ground-glass nodules is especially important, and they are often difficult to palpate, even when the specimen has been resected. In addition, a selected number of biopsies are being performed using robotic techniques, which depend on visual cues to locate a lung mass, but lack tactile cues to pinpoint it.

The described technique has the limitations that the patient must visit the hospital 1 day before the operation to have a CT scan, have the CT performed in the thoracotomy position, and have markers tattooed on the skin. In addition, if the lesion to be resected is beneath the scapula, the shortest point to the lesion may not be a straight vertical line, but rather would require an extrapolated angle when marking the visceral pleura.

The author's technique avoids inserting a wire or needle into the lung parenchyma and therefore should not cause air emboli. Air embolism as a complication of placing a CTguided hook wire that punctures the visceral pleura, or of CT-guided needle biopsies, which also involve puncture of the visceral pleura, have rarely been reported. Avoidance of this complication is one advantage of the described methodology.

Due to the limitations of other marking techniques, we have developed a technique to be used on the morning of robotic surgery for resection of lung lesions that do not abut the visceral pleura and therefore are not easily visualized. Two hours before the robotic resection, the patient is taken to the interventional radiology suite, and the lesion in question is located with CT fluoroscopy. Lidocaine $1 \%$ is used for local anesthesia of the chest wall.

A pasty solution comprised of $1 \mathrm{cc}$ of methylene blue, mixed with collagen and saline to form a gelatinous material, is injected with a 19-gauge trocar needle adjacent to the lesion and in the track leading to the visceral pleura. By adding collagen to the solution, the material remains in the vicinity of the lesion and does not dissipate throughout the lung. The injection of the methylene blue collagen solution along the needle's tract provides identification of the entry site to the visceral pleura overlying the lesion. Should a moderate or large pneumothorax occur, an 8 French pigtail catheter is left in place. The small pneumothorax is monitored conservatively. This technique has been utilized successfully in 18 patients, with pneumothorax as the only minor complication in $2 \mathrm{pa}-$ tients, and only 1 in a patient with moderate chronic obstructive pulmonary disease requiring pigtail catheter placement. This technique demonstrates the location of the nonvisceral surface lung lesion, decreases the time to locate the lesion in robotic cases, and helps in obtaining 